Etnográfica

Revista do Centro em Rede de Investigação em

Antropologia

vol. 20 (1) | 2016

Vol. 20 (1)

\title{
Feitos de semente e pedra: afecção e categorização em uma etnografia na Amazônia
}

Made of seed and stone: affection and categorization in an ethnography in Amazonia

Joana Cabral de Oliveira

\section{(2) OpenEdition}

Journals

Edição electrónica

URL: https://journals.openedition.org/etnografica/4234

DOI: $10.4000 /$ etnografica.4234

ISSN: 2182-2891

Editora

Centro em Rede de Investigação em Antropologia

Edição impressa

Data de publição: 1 fevereiro 2016

Paginação: 143-161

ISSN: 0873-6561

Refêrencia eletrónica

Joana Cabral de Oliveira, «Feitos de semente e pedra: afecção e categorização em uma etnografia na Amazônia», Etnográfica [Online], vol. 20 (1) | 2016, posto online no dia 04 março 2016, consultado o 10 fevereiro 2022. URL: http://journals.openedition.org/etnografica/4234 ; DOI: https://doi.org/10.4000/ etnografica. 4234

\section{(c) (;) (9)}

Etnográfica is licensed under a Creative Commons Attribution-NonCommercial 4.0 International License. 


\section{Feitos de semente e pedra: afecção e categorização em uma etnografia na Amazônia}

\section{Joana Cabral de Oliveira}

Esse artigo tem por base uma etnografia realizada entre os wajãpi, grupo falante de uma língua tupi-guarani, que habita a Amazônia brasileira. Seguindo conexões não lineares traçadas nesse contexto etnográfico, pretende-se mostrar como a "lógica do sensível" (Lévi-Strauss 1970) pode ser um potente guia para percorrer múltiplas searas da vida e do pensamento desse povo, tais como: as classificações botânicas, a constituição de pessoas repletas de conhecimento, a construção de corpos e a cura de doenças.

PALAVRAS-CHAVE: Amazônia, lógica do sensível, afecção, agência da palavra.

Made of seed and stone: affection and categorization in an ethnography in Amazonia - This article is based on an ethnography among the Wajãpi, an Amerindian group that speaks a Tupi-Guarani language and live in Brazilian Amazon. In this context, the concept of "logic of sensible qualities" (Lévi-Strauss 1970) appears as potent guide to following non-linear connections drew by the Wajãpi and enables to go across different scopes of this people's life: botanical classifications, the processes of building wise persons, body construction, and healing actions.

KEYWORDS: Amazon, logic of sensible qualities, affection, word's agency.

CABRAL DE OLIVEIRA, Joana (joanacoliveira2@gmail.com) - Instituto de Biociências da Universidade de São Paulo; Laboratório de Estudos Evolutivos; Centro de Estudos Ameríndios; bolsista FAPESP, Brasil. 


\section{ABERTURA}

Eu seguia ao encalço do velho Ororiwo que me conduzia em passos rápidos pela trilha que chegava à sua aldeia; no chão jazia um fruto peludo que despertou-lhe a atenção. ${ }^{1}$ Ele estancou o andar e o pegou, mostrando-me e dizendo: "Ape'y eu ijupe, jane rova jamõgy remë jane reynavaravu o'ë" ["Ape’y (Apeiba tibourbu) nós o chamamos, quando passamos no nosso rosto a barba nasce”].

A cena singela nos põe defronte à complexidade do campo: como transladar da classificação e identificação de plantas para modalidades de construção do corpo, ações eficazes e tantos outros meandros da vida de um coletivo?

A pesquisa de campo em antropologia nos apresenta o desafio de enfrentar conexões múltiplas e não lineares da forma como um grupo elabora a vida por meio de relações interespecíficas, aspecto que vem há algum tempo nos forçando a desestabilizar a centralidade do humano em nossas reflexões (Bateson 1986), mas que só nas últimas duas décadas de fato se desenvolveu de forma significativa com os trabalhos de autores como Donna Haraway (2003) e Eduardo Kohn (2013).

Frente à tarefa de lidar com uma forma de existência que resiste às nossas concepções e categorias, a já antiga, porém pouco explorada, noção de "lógica do sensível” de Lévi-Strauss (1970 [1962], 2004 [1964]) se mostrou como um potente operador para mover-se entre os diversos âmbitos do cotidiano de famílias wajãpi. ${ }^{2}$

\section{APROXIMAÇÕES AO CONTEXTO}

Ororiwo, que abre esse artigo, é um velho chefe que habita numa das 80 aldeias da Terra Indígena Wajãpi (TIW). Com uma população atual com pouco mais de 1200 pessoas, os wajãpi se espalham em pequenas aldeias pelos 607.000 hectares de terra demarcada em uma área de floresta de terra firme. Organizam-se em grupos locais (wãna kõ) dispersos, que se caracterizam por uma grande autonomia social, econômica e política (Gallois 1986). A ocupação é marcada pela grande mobilidade, pois habitam mais de uma aldeia, deslocando-se conforme os ciclos de chuva e seca: no verão, quente e seco, espalham-se por pequenas aldeias nos limites da TIW, acessadas por rio e/ou longas caminhadas;

l Uma primeira versão desse artigo foi elaborada no âmbito do projeto temático "Redes Ameríndias". Agradeço muito a toda a equipe do projeto, em especial às coordenadoras Dra. Dominique T. Gallois e Dra. Beatriz Perrone-Moisés, bem como à Fundação de Amparo à Pesquisa do Estado de São Paulo (FAPESP) pelo financiamento. Sou muito grata a Valéria Macedo e Pedro Lolli, com quem dividi e discuti as questões aqui abordadas. Agradeço por fim aos pareceristas pelos apontamentos e comentários pertinentes.

2 Entre mestrado e pós-doutorado, ao todo foram, aproximadamente, 16 meses de pesquisa de campo. 
no tempo das chuvas, juntam-se nas chamadas aldeias centrais, acessíveis por estrada e/ou barco, que são na verdade um conglomerado de pequenos pátios (aldeias) nas imediações de postos de assistência (que variam entre escolas, postos de saúde, centro de formação e casa da Funai). Atualmente, o sistema de educação escolar também tem influenciado nessa dinâmica, e as famílias se concentram nas aldeias centrais conforme o calendário de aulas.

Apesar do número crescente de assalariados entre as famílias wajãpi, a alimentação continua a ser oriunda dos produtos da roça, da caça, da pesca e da coleta. Esse modo de vida resulta em uma dinâmica cotidiana muito própria, caracterizada por incursões diárias pelas áreas de floresta de terra firme, capoeiras, roças, igapós e igarapés. Os wajãpi possuem, assim, um conhecimento acurado sobre os seres vivos e as paisagens com os quais se relacionam na elaboração de uma boa vida, saberes que emergem de uma atenção delicada e profunda sobre as plantas, os animais, os solos, as rochas etc., o que nos conduz à proeminência da lógica do sensível nesse contexto.

\section{A LÓGICA DO SENSÍVEL}

Conceitualmente, a concepção de uma lógica do sensível é apresentada por Lévi-Strauss na obra O Pensamento Selvagem (1970 [1962]), cujo mote é a descrição e a análise de um modo outro de pnsamento, o qual se contrapõe à ciência moderna não por suas operações cognitivas, mas pelos trajetos de seu modo de conhecer.

Tomando como ponto de contraste as teorias que relegavam o pensamento dos povos de tradição oral aos interesses meramente utilitaristas ou afetivos e o caracterizavam por um baixo nível de abstração, Lévi-Strauss demonstra por meio de uma profusão vertiginosa de dados etnográficos que o conhecimento produzido por tais grupos lida com ideias abstratas e é movido pela mesma necessidade de ordenação e atribuição de sentido que o pensamento científico, estando, pois, em um mesmo patamar de desenvolvimento intelectual.

Ainda que instigada pela curiosidade arguta, pelo prazer estético e intelectual de ordenar o cosmos, bem como apoiada em uma observação minuciosa, a "ciência do concreto" se distancia do pensamento domesticado (a ciência moderna) por seus processos e interesses, operando por meio de uma lógica do sensível: "[É] como se as relações necessárias, objetivo de toda a ciência - seja ela neolítica ou moderna - pudesse ser atingido por dois caminhos diferentes: um muito perto da intuição sensível e outro muito afastado" (Lévi-Strauss 1970 [1962]: 36).

A proximidade da "intuição sensível" é a escolha de determinado pensamento de lidar com qualidades concretas - captadas em todas as medidas pelos cinco sentidos - na produção de uma reflexão lógica, isto é, no estabelecimento de relações necessárias que permitam tornar o mundo inteligível. O caminho 
trilhado pelo pensamento selvagem opera com um amálgama entre sensível e inteligível, concedendo uma existência lógica a oposições como duro e mole, liso e rugoso, cru e cozido, fétido e cheiroso...

Diferente do pensamento científico, que opera com conceitos cada vez mais apartados de seus referentes, a ciência do concreto lida com signos - elementos a meio caminho entre o conceito e a imagem (talvez o melhor seria dizer entre o conceito e o percepto, uma vez que o código visual é apenas um dos operadores em jogo): "Como a imagem, o signo é um ser concreto, mas assemelha-se ao conceito por seu poder de referência: um e outro não se referem, exclusivamente, a si próprios, podem substituir outra coisa que a si" (Lévi-Strauss 1970 [1962]: 39).

A concepção de signo usada por Lévi-Strauss é inspirada na definição de Ferdinand de Saussure acerca do signo linguístico - formado pela relação entre imagem acústica e conceito, significante e significado respectivamente. ${ }^{3}$ À diferença do conceito, o signo mantém um nexo direto com um mundo, tal como ele é percebido por aqueles que o habitam: “[...] uma das maneiras, ao menos, de o signo opor-se ao conceito prende-se a que o segundo pretende ser integralmente transparente à realidade, enquanto que o primeiro aceita, e exige mesmo, que uma certa densidade de humanidade seja incorporada a essa realidade" (Lévi-Strauss 1970 [1962]: 41).

Podemos compreender essa "certa densidade de humanidade" como a percepção, passo elementar no movimento de conhecer e construir categorias sensíveis. A percepção deve ser entendida aqui como um "engajamento do ser no mundo", para tomarmos de empréstimo a expressão de Tim Ingold (2000), ou seja, ela não é absoluta e universal, mas como enfatiza Lévi-Strauss (2004 [1964]) na abertura das Mitológicas, trata-se antes de um processo elaborado coletivamente. Ainda que as categorias concretas de quente e frio, duro e mole sejam "definíveis com precisão pela mera observação etnográfica" (Lévi-Strauss 2004 [1964]: 19), apesar de sua concretude elas precisam ser descritas e compreendidas "sempre a partir do ponto de vista de uma cultura particular" (2004 [1964]: 19): o queimado ou o podre não têm valores semânticos absolutos, mas se inserem em diferentes feixes de relações, os quais são tecidos de modo singular por cada grupo de sujeitos. A opacidade humana fica, assim, a cargo de uma percepção construída, que pode ser compreendida na chave de uma "educação da atenção" tal como formulada por Ingold (2010). A educação da atenção funda-se na ideia de que os processos de socialização recaem sobre o ensino de maneiras de percorrer sensorialmente um mundo (modos de ver, ouvir, sorver, provar, tocar), ou seja, um orientar da atenção trilhado na

3 “O signo linguístico une não uma coisa e uma palavra, mas um conceito e uma imagem acústica. Esta não é o som material, coisa puramente física, mas a impressão (empreinte) psíquica desse som, a representação que dele nos dá o testemunho de nossos sentidos" (Saussure 1995 [1916]: 80). 
convivência entre parentes, e não sobre a transmissão de qualidades concretas em si. Aqui, inspirada pela proposta de Kohn (2013) e Haraway (2003), diria que o processo de educação da atenção não se restringe ao compartilhar a vida entre humanos, mas abarca também uma relação de convivência interespecífica, onde o engajamento com outros seres molda a percepção, sendo, por exemplo, o ape'y (o fruto peludo) um sujeito da relação perceptual.

Voltando à ciência do concreto, será por meio desse vasto material fornecido pela relação entre mundo e sujeito que o pensamento selvagem operará à maneira de um bricoleur, criando inteligibilidade por meio do estabelecimento de relações entre elementos do mundo e categorias sensíveis. ${ }^{4}$ De acordo com Keck, "O bricoleur lévi-straussiano é um esteta: ele combina as partes da matéria sensível a fim de lhes fazer produzir arranjos sempre novos, pelo mero prazer da combinação" (2004: 50). ${ }^{5}$ É tal modo de combinar, de relacionar, que Lévi-Strauss denomina de "lógica do sensível".

\section{DURO E NÃO DURO}

Certa manhã Majuware resolveu ir trabalhar na derrubada de uma porção de mata que seria seu futuro roçado. Ele reuniu alguns parentes para ajudá-lo. Seguiram para a tarefa seus três cunhados adultos munidos de machados, um jovem com um terçado, seu pequenino filho e uma de suas irmãs que carregava um terçado e um panelão de kasiri miti (bebida de mandioca não fermentada). A área havia sido previamente limpa, delineando os limites do trabalho. Os homens empunhando os machados talhavam as árvores mais grossas, enquanto a mulher e o menino cortavam as árvores mais finas com seus facões. Todos desferiam os golpes em uma mesma direção, mas não cortavam os troncos por completo, deixavam as árvores seguras por uma faixa de madeira intocada. Essa técnica é realizada para que a última árvore (a única a ser cortada inteiramente) se incumba de arrastar as demais consigo para o chão, poupando, dessa maneira, algum esforço.

Foi nesse contexto que um dos jovens cunhados estancou as machadadas e perguntou ao dono do futuro roçado: "Moma'e põ yvyra tairo" ["Que árvore é essa, cunhado?"]. Majuware parou, fitou o tronco, seguiu com os olhos até alcançar a copa e fez a típica pergunta retórica: "Moma’e si põ" ["Como se diz mesmo?"]. Depois de alguns instantes, respondeu: "Akusityry, eu ijupe!"

4 Além de caracterizar o pensamento selvagem, a forma do texto e do argumento de Lévi-Strauss fazem operações semelhantes: ao opor as figuras do bricoleur e do engenheiro, o autor produz uma explicação por meio de signos e não de conceitos.

5 No original: "Le bricoleur lévi-straussien est un esthète: il combine des parties de la matière sensible en vue de leur faire produire des agencements toujours nouveaux, pour simple plaisir de la combinaison" (Keck 2004: 50). 
[“Akusityry ${ }^{6}$ se fala para ela!"]. O jovem cunhado então concluiu em alto e bom tom: "Yvyra ãtã!" [“Árvore dura!"]. Findo o dia, antes de nos encaminharmos de volta à aldeia, notei uma árvore que se mantinha intacta no meio da clareira. Perguntei seu nome e porque não havia sido derrubada, ao que me responderam: "Kurata’y noityi, yvyra ãããtã ajawyi" ["Pé de Kurata (Couratari sp.) não se derruba, porque é árvore duuura”].

Nas formas classificatórias dos wajãpi, a dureza aparece na estruturação de duas categorias opostas: yvyra ãtã (árvores duras) e yvyra nãtãi (árvores não duras). ${ }^{7}$ Arduamente apreendidas na prática, como se pode notar, as árvores duras são percebidas e se constituem como uma categoria sobretudo ao longo da derrubada de uma porção de floresta. É preciso pontuar que nesse contexto etnográfico não faz sentido falar em um sistema de classificação, temos antes uma multiplicidade de taxonomias estruturadas por princípios diversos que entram em ação conforme o contexto e as intenções de quem classifica (Cabral de Oliveira 2008, 2012). Algumas qualidades sensíveis, como a dureza, atravessam essas diferentes classificações, e são relevantes para além da importante oposição entre plantado (temitãgwerã) e não plantado (temitãe'ã).

Dessa forma, a dureza não é um critério de qualificação exclusivo das árvores da floresta $\left(k a^{\prime} a\right)$, ela aparece também na apreciação e no trabalho com as espécies vegetais, em especial aquelas que são plantadas (temitãgwerã). Os wajãpi possuem um léxico minucioso ${ }^{8}$ para falar da maturação de frutas e tubérculos; algumas espécies são ditas estarem ipirã ( $i$ - = pronome possessivo de 3. ${ }^{a}$ pessoa; - pir $\tilde{a}=$ vermelho) quando maduras, esse é o caso do mamão (Carica sp.), do caju (Anacardium occidentali), da pupunha (Bactris gasipaes) etc. Outro conjunto tem sua maturação plena qualificada como omy katu (omy= escuro; katu = bem, bonito), esse é o caso do açaí (Euterpe oleracea) e da bacaba (Oenocarpus bacaba). Outros são ditos estarem ipije ( $i-=$ pronome possessivo de $3 .^{a}$ pessoa; - pije $=$ cheiroso) como o cupuaçu (Theobroma grandiflorum). Poderia seguir enumerando mais exemplos, mas esses são suficientes para apresentar aquele que nos interessa: algumas plantas têm o ápice de sua maturação marcado pela dureza e, por isso, são ditas estarem ãtãroma (ãt $\tilde{a}=$ duro; $-r \tilde{o}=$ partícula que indica transformação; $-m a=$ completivo). A mandioca (Manihot esculenta), a batata (Ipomoea batatas), a cuia (Crescentia cujete), a cabaça, o cará-moela

6 Árvore não identificada.

7 Há uma densa discussão acerca das categorias denominadas life form, tal como árvore, cipó, arbusto etc. (Berlin 1992; Hunn 1977) que não irei recuperar aqui. Contudo, vale pontuar que tais categorias aparecem em um dos sistemas de classificação wajãpi, o qual se estrutura por critérios morfológicos. Ainda que tais categorias de "forma de vida" se apresentem, elas só operam com as plantas não cultivadas, ou seja, são internas à categoria temitãe'a a. Há assim uma diferença na classificação de plantas cultivadas e não cultivadas que reflete em sistemas distintos, os quais são fundados por princípios diversos, algo que reafirma a importância dessa cisão entre plantado e não plantado para os wajãpi.

8 Para mais exemplos desse léxico e seu uso, ver Cabral de Oliveira (2006: 180-184). 
(Dioscorea bulbifera) e o sisal (Agave ssp.) quando estão no ponto de colheita são qualificados como "plenamente duros" (ãtãrõma). Já a jaca madura é dito estar mole, ipyи $\left(i-=\right.$ pronome possessivo de $3 .^{a}$ pessoa; $-p y u=$ mole $)$.

A dureza é um critério importante também na classificação e qualificação das mandiocas. Os trabalhos femininos, quase diários, de preparação de alimentos à base desse tubérculo exigem um árduo processamento em ralos manuais. Dessa atividade comumente toma parte um grupo de mulheres ligadas por laços de consanguinidade, o que inclui pequenas meninas que fazem dessa uma atividade lúdica de aprendizado. Nesse contexto há uma apreciação e uma apreensão minuciosas das texturas e da dureza das diversas variedades de mandioca. ${ }^{9}$ Esse, aliás, é um critério importante no processo de identificação: quando se pergunta o nome de uma variedade é comum partirem a raiz para ver a combinação de cores que a compõem, bem como para sentir sua dureza.

O aprendizado da dureza das árvores, das mandiocas e de tantos outros vegetais ocorre, assim, nas ocasiões de trabalhos ordinários: ao sentir através do machado o esforço necessário para se talhar um tronco; ao empenhar mais ou menos potência para ralar uma mandioca; ao constatar nas pontas dos dedos a maturação de uma cuia ou das folhas de sisal. Além de uma percepção fina apreendida nesses eventos de interação interespecífica, o compartilhar de asserções sobre tais qualidades é fundamental nesse processo de construção de categorias e saberes.

A categorização das plantas em duras e não duras constitui-se, assim, em uma relação direta com uma experiência corporal (que envolve um engajamento em uma relação com cada espécime) e uma troca de apreciações (que envolve o compartilhamento de enunciações sobre o que se percebe). Essa questão abre um gancho para as proposições de Lakoff (1990) da mente encorporada (embodied mind). Lakoff se encaixa em um movimento teórico de reatar corpo e mente no âmbito dos estudos de cognição, alicerçando a categorização (e o pensamento de modo geral) na experiência corporal: “[...] sistemas conceituais emergem da experiência corporal e fazem sentido em termos dela; o núcleo de nossos sistemas conceituais está diretamente fundado na percepção, no movimento corporal, e na experiência dos aspectos físico e social" (Lakoff 1990: xiv). ${ }^{10}$

Em certo sentido, Lakoff se alinha a outros autores que tratam a experiência como cerne do conhecimento, tal como Ingold (2000), que intenta desmanchar as fronteiras entre corpo e mente, sujeito e ambiente. Com o objetivo de

9 Vale notar que em meu levantamento cheguei a um total de mais de cem nomes de variedades de mandioca, havendo mesmo algumas mulheres que podem chegar a ter por volta de vinte em suas roças. 10 Traduzido do original em inglês: "[...] conceptual systems grow out of bodily experience and make sense in terms of it, the core of our conceptual systems is directly grounded in perception, body movement, and experience of physical and social character" (Lakoff 1990: xiv). 
delinear um modelo cognitivo, Lakoff repõe os processos de categorização em uma prática ordinária, onde a experiência se torna o elo de fusão dessas grandes divisões.

Apesar da importância do corpo nesses movimentos de conhecer, não se pode esquecer a relevância e a centralidade da palavra, um compartilhamento reflexivo sobre o que se experimenta. O partilhar de vivências, a troca de apreciações, é um processo fundamental para consolidar generalizações e alicerçar categorias. ${ }^{11}$

Além disso, nesse movimento de descentrar o humano das análises antropológicas, é importante frisar que esse engajamento se dá com uma multiplicidade de seres, no caso aqui enfocado com algumas plantas, que são agentes da relação. Cada vegetal apresenta suas particularidades, fazendo com que as pessoas sejam afetadas e sejam motivadas a reagir a elas nesse processo. Não é toda árvore que é deixada intacta no meio de uma roça, mas sim aquele kurata da roça nova de Majuaré; não é qualquer fruto que permite aos homens ter barba, mas sim o fruto peludo que a árvore ape’y produz. Reformulando a proposição de Lakoff, os sistemas conceituais emergem não só das experiências corporais, mas das relações que se travam com uma miríade de seres para além da humanidade.

\section{PERECÍVEL E IMPERECÍVEL}

Se, por um lado, a dureza se constitui como um operador importante na classificação de plantas, fundamentando categorias que permitem orientar ações como empregar mais ou menos força para ralar uma mandioca, deixar de derrubar algumas espécies de árvore etc., em um movimento em que o corpo se molda e apreende um mundo, por outro lado, em contextos distintos, os wajãpi enfatizam o inverso: é a dureza de determinados elementos mundanos que cria e age sobre os corpos, numa perspectiva que ressalta a agência e autonomia de plantas, animais, pedras etc., o que é reconhecido e captado, por exemplo, em algumas fórmulas enunciativas.

Os wajãpi possuem encantações (jërõnïga) formadas por enunciados ritmados que têm alta potência agentiva: eles são capazes de aplacar alguns males. ${ }^{12}$

11 As colocações de uma mente encorporada, somada aos dados apresentados aqui, podem conduzir apressadamente à conclusão de que há um primado do ambiente sobre o corpo. Entretanto, os wajãpi possuem uma série de falas eficazes que agem sobre o mundo, garantindo, por exemplo, o sucesso de suas plantações, o afastamento de cobras e onças etc. (Cabral de Oliveira 2012). Esse conjunto de falas eficazes apresenta uma inversão desse primeiro movimento descrito (de um mundo que molda um corpo, que impõe um saber).

12 Gallois (1988) aponta uma diferenciação entre dois tipos de cantos, em relação ao que chamo e grafo (acompanhando a grafia estabelecida pelos professores wajãpi) como jërõnïga: "wyró-jinga" que seriam os cantos de cura e "jirõ-jinga" que seriam cantos de agressão (feitiço). Como em meu campo não conheci essa diferenciação, nem ouvi falar de cantos agressivos, provavelmente por ser esse um tipo de saber perigoso, atribuído sempre a outros, como nos mostra a autora, não trato dessa [continua] 
De conhecimento comum, os jërõnïga são pronunciados em tom baixo junto ao enfermo para curar dor de dente, picada de cobra, desmaios etc.

As encantações usadas para dor de dente, por exemplo, agenciam a dureza/moleza de alguns elementos, desdobrando esse par em um jogo de qualidades sensíveis que constituem uma cadeia de relações duais, conectando diversos âmbitos da vida wajãpi. Vejamos sua execução:

“Kaikusi ipi nokõ nãi jayi/ moma’e kãgwerã osu’u remë ipi nokõ nãi jayil Ta’e vo jë iko nerãi nel tay e'ã wetë nerãi”".

"Onça a que não dói o dente/ que quando morde osso o dente não dói/ Como ela seu dente deve ficar/ seu dente não deve doer."

Essa fórmula remete diretamente à constituição dos seres (uma ontogênese) em outro tempo-espaço - o das origens - conduzindo a um conjunto de narrativas das experiências vividas pelos primeiros homens (taivïgwerã). ${ }^{13}$ Entre as diversas escolhas feitas pelos taivïgwerã , algumas marcam a mortalidade dos homens por meio de um corpo perecível. Uma dessas escolhas refere-se ao material de que foram feitos os dentes humanos: contrariando o conselho de um demiurgo, janejarã, os homens optam por inserir em suas gengivas a mole semente de pariri (Heliconea sp.) ao invés da dura pedra tãsï (quartzo branco), que é, então, destinada ao jaguar, garantindo imperecibilidade aos seus dentes - aspecto que é confirmado nos tempos de hoje a cada vez que uma onça é morta e tem seus caninos arrancados, momento em que podem ser tocados e admirados por sua dureza e brancura. ${ }^{14}$

A encantação acima equaciona justamente a dureza dos dentes de jaguar e a moleza e perecibilidade dos dentes humanos, evocando a ontogênese de ambos. Desse modo constitui-se uma afecção no sentido deleuziano: uma mudança de qualidade ou estado de um corpo-pessoa alterado por meio de outro corpo-pessoa, ou seja, uma mistura entre corpos.

Em outra fórmula, esse jogo é repetido com uma pequena variação:

“Yryapyry pekajã ma'ë tãsinary tui ipi ronõ/ Irõwã gatu kajã ma'ë ipi ronõ/ Ta’e vo jë iko nerãi në".

diferenciação. A autora também transcreve alguns desses cantos de proteção e cura. Para mais detalhes, ver Gallois (1988: 281 e apêndice 4).

13 Taivïgwerã pode ser traduzido também como "antepassados genéricos", na medida em que não se conhecem seus nomes e relações genealógicas. Entretanto, como apontou Gallois (1993: 23-25), esse termo deve ser compreendido também como um "conceito de temporalidade", podendo ser entendido como um contexto de transmissão: quando homens e animais falavam uma mesma língua.

14 Outra escolha narrada é a recusa dos taivïgwerã de entrarem em um caldeirão de água fervente, tal como janejarã lhes sugere. As cobras não temem a quentura e entram na água fervente, o que lhes rende a imortalidade e o rejuvenescimento por meio da troca de pele. 
"Na nascente que tem pedra tãsi/ Lá que está bem frio/ Como ela seu dente deve ficar".

Nessa encantação a pedra tãsi é evocada diretamente, remetendo tanto a sua dureza como a sua qualidade térmica - a frieza. Localizando-se dentro ou próximo as nascentes, tãsi porta uma frieza intrínseca, que deve aplacar o calor da inflamação de um dente podre.

Em ambas as encantações, o par duro/mole se desdobra em frio/quente, são/purulento, imperecível/perecível e vida/morte. Todo esse jogo aparece sob a égide de dois índices: pariri e tãsi.

Proponho aqui marcarmos uma pequena distinção nos modos de operação dos signos, tal como estabelecido por Lévi-Strauss ao caracterizar a lógica do sensível. A referida distinção remete diretamente a uma diferenciação dos contextos aqui em pauta: se de um lado há a operacionalização de categorias classificatórias - como yvyra ãtã (árvores duras), kurata (árvore kurata), mani’o (mandioca), jawarã (onça), pariri (Heliconea sp.) etc. - e de qualidades sensíveis como ãtã (duro), ipyu (mole), irowã (frio), aku (quente) etc. - que emergem em contextos ordinários da produção da vida, de outro lado há os momentos específicos de uso dos jërõgïga e de procedimentos de construção de corpos (descritos adiante), onde as categorias classificatórias são pensadas e mobilizadas a partir de índices, ou seja, de elementos concretos que obliteram um complexo jogo de qualidades sensíveis.

A noção de índice remete necessariamente a Charles Peirce, que o define como um signo indicador a partir do qual se pode fazer inferências (apud Gell 1998). Na proposta de antropologia da arte de Alfred Gell, o autor acrescenta ao conceito peirciano uma carga semântica de agentividade. Eduardo Kohn (2013), por sua vez, também toma de empréstimo o conceito de Pierce na proposição de uma "antropologia para além do humano", na qual a linguagem passa por uma "provincialização" (Kohn 2013: 38-42) e deixa de ser um atributo exclusivo ao homem. Segundo Kohn, a propriedade característica do índice é sua capacidade de significar mais do que ele representa, contrapondo-se à noção de ícone, que representa a ele mesmo (2013: 32-33). Aqui as duas características ressaltadas por ambos os autores são fundamentais para justificar a escolha do conceito de índice, isto é, sua capacidade de agência e de significado estendido.

Chamarei, assim, de índices os signos que, em determinados contextos, tornam-se elementos indicadores de um conjunto de atributos sensíveis, os quais estão eclipsados em um ser concreto e que produz um efeito, uma transformação em outros corpos.

Essa caracterização de modos distintos de manejar os signos conduz a uma questão abordada em O Pensamento Selvagem: a heurística da noção de espécie. A espécie, para Lévi-Strauss (1970 [1962]), aparece como um operador médio que articula diferentes níveis de uma classificação, os mais abstratos, ou seja, 


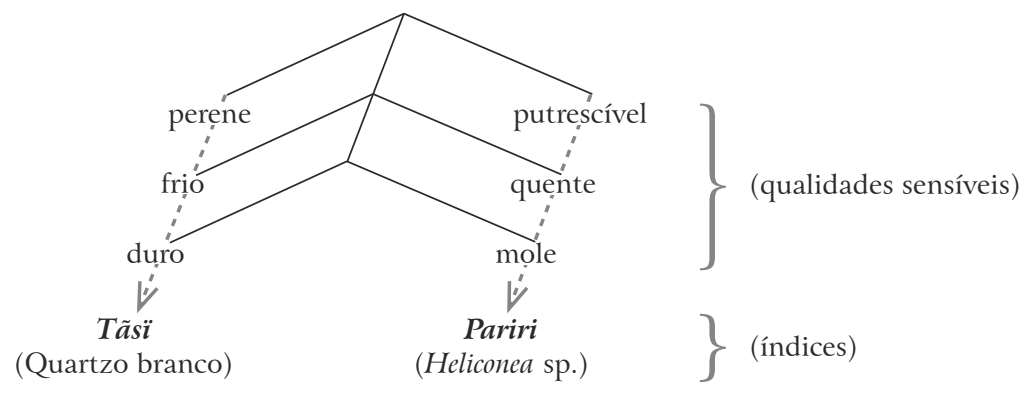

Figura 1 - Esquema da relação entre índices e qualidades sensíveis.

as categorias de maior inclusão, e os mais concretos, que se situam ao nível do indivíduo (do espécime), onde se assenta o nome próprio. A espécie permitiria, assim, transladar de um polo a outro: da universalização à particularização, do abstrato ao concreto. Daí sua proeminência no pensamento selvagem.

A espécie aparece, pois, como um instrumento conceitual, onde o que está em jogo é uma complexa combinação de características de cada grupo de seres, suas cores, texturas, comportamentos, sons, cheiros etc., o que leva Lévi-Strauss a concluir: "Essa matriz tridimensional, verdadeiro sistema por meio de um animal, e não o próprio animal, constitui o objeto do pensamento e fornece o instrumento conceitual" (1970 [1962]: 176).

Todavia, manter o termo espécie para denominar esse tipo de signo nos tempos atuais significaria ignorar a complexa discussão e disputa em torno desse conceito (Rapini 2004). Há na biologia diferentes acepções em jogo. O conceito biológico de espécie se alicerça sobre a ideia de isolamento reprodutivo: para ser considerada uma espécie é preciso gerar descendentes férteis. Trata-se, pois, de uma relação do âmbito do dado, ou seja, a espécie é entendida como uma entidade biológica. O conceito evolutivo de espécie segue rota semelhante, definindo a espécie como uma linhagem que evolui separadamente de outras. Por fim, para mencionar uma última entre outras concepções, há aquela qualificada como conceito taxonômico de espécie, que se refere apenas a um nível classificatório de um sistema, não sendo, portanto, compreendida como uma entidade biológica em si, ou ligada a uma corrente teórica, mas apenas um táxon, uma classe entre classes.

Não há dúvidas que Lévi-Strauss usa "espécie" nesta última acepção. Esclarecido esse ponto poderíamos, a princípio, dar continuidade aos termos do autor. Contudo, enquanto um táxon, muito do que Lévi-Strauss menciona em seus exemplos não se encontra ao nível de espécie, mas sim de gênero. Note-se que a grande maioria dos antropólogos e dos linguistas que se dedicaram ao estudo de sistemas classificatórios nativos aponta como nível taxonômico mais proeminente o de gênero (Lakoff 1990; Hunn 1977; Berlin 1992). 
Contudo, o ponto em questão aqui não é fixar um nível taxonômico como o mais elementar, mas notar que há um conjunto de categorias que estariam em um nível médio do sistema e que seriam, justamente por isso, mais proeminentes, uma vez que funcionam como um eixo de passagem, um operador elementar. Nesse sentido, opto por me desfazer dos termos de Lévi-Strauss, mas não de suas ideias, parece-me que a lógica motriz permanece.

O cerne da questão é que as categorias usadas para nomear um conjunto bem delimitado de seres, tais como tapi'irã (anta), jãvi (jabuti), mani'o (mandioca), pariri (Heliconea sp.) etc., que podem ser enquadradas como espécie ou gênero segundo a taxonomia ocidental e que podem ser subdivididas em categorias menos abrangentes de acordo tanto com a classificação wajãpi como com a científica, são operadores médios, pois articulam níveis distintos de abstração e permitirem a transição entre diferentes domínios dos saberes e do cotidiano wajãpi. ${ }^{15}$

Ao ser transladado para práticas eficazes (encantações e construção da pessoa), esse nível categórico mediano passa a figurar como índice de categorias sensíveis como as de duro e mole, quente e frio etc. Quando evocados nos enunciados agentivos, os índices equacionam junção e disjunção entre distintos seres por meio de uma palavra eficaz. Voltando aos exemplos etnográficos, o primeiro enunciado aproxima jaguar e homem com o objetivo de afastar homem e pariri; o segundo junta homem e tãsï para operar uma cisão entre homem e pariri. As frases das encantações intentam executar, por meio de índices, uma transformação da moleza dos dentes humanos em dureza, da quentura em frieza e do podre em são.

Há mais cantos usados no tratamento da dor de dente que reforçam esse procedimento. Pode-se evocar as qualidades dos dentes de ka’i (mico, Mico ssp.), que são pontiagudos e duros, sendo capazes de furar tabocas, ou referir-se à uwa (caranguejo) cuja hipermoleza do aparelho bucal pode ser transferida aos dentes enfermos fazendo-os caírem rapidamente para findar a dor.

Toda a eficácia dessas encantações está, pois, depositada sobre dois princípios: a potência agentiva da palavra e a operacionalização de equações sensíveis por meio de índices que são elementos agenciadores de afecções corporais.

As encantações para desmaio (manomano) também são emblemáticas desse jogo de qualidades sensíveis via índices que compõem afecções. Eis dois trechos de jërõnïga proferidos junto a um desfalecido:

"Ay kae penokõ jakãnopã remë/ nomanoi, nomanoi"

"Preguiça real que quando batemos na cabeça/ não morre, não morre"

15 Esses táxons (tapi'irãa, jãvi e mani'o), entre outros, podem ser subdivididos em categorias menos inclusivas (como espécie, subespécie e variedade): jãvi ee (jabuti mesmo) e jãvi wasu (jabuti grande); mani'opirã (mandioca vermelha), mani'o tawa (mandioca amarela), mani'o yvyra (mandioca árvore) e assim por diante. 
“Javi, jãvi, jãvi/ nomanoi, nomanoi jakãnopã remë"

"Jabuti, jabuti, jabuti/ não morre, não morre quando batemos na sua cabeça"

Aqui, são evocados a dureza da cabeça de preguiça - apresentada na dificuldade de matá-la com uma cacetada - e a afamada resistência à morte de jabuti, uma vez que o desmaio (manomano) é entendido como um tipo de morte (mano), isto é, de afastamento do princípio vital - 'ã. Note-se, ainda, que os wajãpi possuem um longo ciclo de narrativas, consideradas por eles como histórias para criança, onde jabuti, personagem principal, resiste por sua sapiência e corporalidade (em especial por seu duro casco) a diversas disputas e tentativas de assassinato. O jabuti é um índice da resistência à morte, que é apreendido em distintas dimensões e contextos, tanto nas suas desventuras narradas às crianças, como na prática quando é "coletado" pelas famílias wajãpi, momento em que seu casco duro é apalpado, seu difícil esquartejamento é sentido através do facão e o pulsar do coração do bicho já dilacerado é observado.

Nesse caso, não posso me furtar a desvelar um jogo de oposições sensíveis recorrente: duro/mole :: vida/morte, desdobramento notado por Lévi-Strauss (2004 [1964]: 184-186) ao tratar do tema da vida breve em um conjunto de mitos onde a morte irrompe devido à resposta dos primeiros homens ao chamado da madeira (putrescível e mole) e não ao da rocha (imperecível e dura).

\section{BOCA MOLE, BRAÇO DURO}

Mas, como nos ensina Lévi-Strauss, as oposições nas cosmologias ameríndias não são fixas, muito menos possuem valor absoluto. Assim sendo, duro/mole podem assumir valores distintos em outro feixe de relações e articular-se a outras dualidades concretas. É isso que ocorre quando notamos sua operacionalização na construção de corpos capazes de conhecer.

Tema extenso e complexo, a construção da pessoa wajãpi envolve vários mecanismos (Gallois 1988; Rosalen 2005; Cabral de Oliveira 2012): resguardos, controle da alimentação, ensinamentos, picadas de formigas etc. Focar-me-ei em alguns desses procedimentos, os quais conformam um conjunto aberto e diversificado de formas de capacitar corpos-pessoas a aprender.

A capacidade de falar é construída na infância por meio de algumas dessas práticas. Uma das mais difundidas é a ingestão de língua de japiim (Corvídea sp.), ação que é realizada juntamente com uma fórmula enunciativa: "eporegeta katu japu vo kene" ["fale bem como japiim"]. Ave famosa por imitar outros pássaros, intenta-se por meio de uma aproximação parcial com japiim (ingestão da língua) e de uma fala eficaz transmitir a capacidade desse pássaro à criança, para que ela possa aprender línguas estrangeiras facilmente.

O rito de picadas de formigas tapija'i também pode realizar a capacitação para o falar bem (de modo eloquente) ou para aprender outro idioma. As ferroadas 
marcam o final da reclusão da menarca - momento em que a púbere sai de sua casa, para que ocorra a aplicação sobre seu corpo das tramas de palha repletas de formigas, todas presas com os ferrões na mesma face. Nessa circunstância, além da jovem, as demais crianças da aldeia recebem algumas picadas, mas só devem aplicar as formigas os sabidos: as mulheres que trabalham bem nas roças, os bons caçadores, os bons artesões, as boas tecelãs, aqueles que falam e cantam bem, pois tais capacidades serão transmitidas por meio das ferroadas. Por esse motivo fui exortada a picar diversas crianças para que viessem a aprender o português tão bem quanto eu. Da mesma forma fui eu picada por homens e mulheres mais velhas na esperança de vir a falar a língua wajãpi.

A capacidade de aprendizado de um idioma estrangeiro é qualificada pelos wajãpi em termos de rigidez e maleabilidade da língua. Ao se referirem a minha suposta facilidade em aprender o wajãpi, era comum que dissessem: "Nejuru savevojë porëgeta" ["Sua boca é mole/suave para falar"]. Assim como muitos wajãpi justificam sua suposta dificuldade com o português devido à dureza de seu aparelho fonador: "Nakuwai karai ayvu, ejuru ãtã!" ["Não sei a fala dos brancos, minha boca é dura!"]; "Janepekõ ãtã" ["Nossa língua é dura"]. Para falar bem é preciso ter uma boca e língua maleáveis, que se dobrem frente aos fonemas do estrangeiro. Todavia, se a capacidade de falar novos idiomas passa pela construção de uma boca e língua moles, qualidade transmitida por meio da proximidade parcial e controlada com uma alteridade (um forasteiro ou uma ave), outras habilidades requerem um corpo duro.

Durante um de meus campos, ao chegar a uma nova aldeia minha anfitriã veio apresentar-me uma de suas filhas, a qual possuía algum problema de nascença. Ela me disse: "Ememyry notekokuwai katu. Ijyva nokuwai mani'o kyry" ["Minha filha não entende bem. O seu braço não sabe ralar mandioca"]. Segundo a mãe, os braços dela eram fracos e moles (savevojë) e por isso eram inaptos ao trabalho de ralar. Os braços devem ser duros e fortes para o processamento da mandioca, assim como as pernas devem ser robustas, rígidas e potentes para suportar as longas caminhadas e o peso dos panakõ (as mochilas feitas de folha de açaí).

Certa feita, enquanto observava Pisika destrinchando uma anta, ela convocou seus netos: "Ejo tapoanõ epary" ["Venham meus netos, para eu lhes passar unguentos"]. Enquanto as crianças a rodeavam, ela esfregou a mão no humor melado do joelho de anta e untou os tornozelos e canelas de seus netos repetindo a frase: "Ene kasia'y panakõ movy" ["Você seja forte ao carregar panakõ"]. Eu lhe indaguei sobre o motivo de tal ação e ela explicou: "Ikasi omovy panakõ. Yvytyry remë nikaneõi, nimarai ata. Awï vo tapi'ira" ["Eles serão fortes para carregar panakõ. Nas montanhas não se cansarão, não se acidentarão. Tal como a anta"].

A anta, maior mamífero da Amazônia, por sua conhecida habilidade de subir montanhas carregando seu tamanho excessivo, apresenta-se como um índice das capacidades de aguentar peso e de se deslocar facilmente, atributos 
muito valorizados pelos wajãpi. Não por acaso a velha Psika recorreu a uma consubstanciação parcial de seus netos com a anta. Como em tantos outros procedimentos de capacitação e construção de corpos, conjuga-se uma proximidade entre elementos devido a suas qualidades comportamentais e sensíveis; nesse caso, tais aspectos são operacionalizados como afecções juntamente com uma fala eficaz.

As qualidades sensíveis da anta fazem dela, aliás, um excelente índice de intensidade e grandeza: o enorme peso para se transportá-la quando morta, o que requer que o caçador vá buscar ajuda na aldeia; a farta quantidade de carne, que é largamente distribuída; o grande volume de fezes que é retirado de suas tripas durante o esquartejar; o odor excessivamente fétido emanado dessa operação; e seu robusto e forte corpo - tudo em exagero.

Tapir, assim como os outros animais e plantas aqui mencionados, constitui um índice que condensa em si diversas qualidades sensíveis, as quais se prestam tanto para operar transformações eficazes (como em sua participação na elaboração de corpos-pessoas), como para categorizar e conceitualizar elementos do cosmos.

Voltando ao âmbito das classificações botânicas, note-se que tapi'irã (anta) compõe o epíteto de algumas variedades de cultivares: nãnã tapi'irã [abacaxi -anta], variedade de abacaxi que fornece grandes frutos; asikaru tapi'irã [cana de açúcar anta], variedade de cana que possui caules mais grossos; a árvore tapi'irã yvyra [árvore anta], assim denominada pelo seu enorme porte etc.

\section{CATEGORIAS, ÍNDICES E AFECÇÕES: \\ EXECUÇÕES DA LÓGICA DO SENSÍVEL}

A opção por denominar determinadas qualidades sensíveis, tais como a dureza, ora como categoria, ora como afecção - oscilação que não deve ter passado despercebida ao leitor - deve-se ao intuito de marcar contextos distintos de operacionalização dessas qualidades. Se nos encantamentos, nos processos de capacitação para o aprendizado e na fabricação de pessoas apropriadamente humanas a ideia de afecção ganha relevo, no âmbito das classificações e dos saberes ordinários a proeminência é da noção de categoria (classe, grupo). O que se pretende marcar com tal léxico é a distinção entre situações em que o potencial agentivo dos habitantes do mundo produz transformações e os momentos em que tais seres são apenas apreciados quanto às suas qualidades, sem afetarem os corpos daqueles que lidam com eles.

Ainda que se opte por marcar uma distinção entre dois conjuntos de contextos de enunciação e operacionalização das qualidades sensíveis, ambos estão intimamente conectados. De forma paradoxal, a opção por produzir tal cisão parece útil para qualificar as relações que os unem de maneira imiscuída - afinal, é preciso diferenciar para relacionar. 
Se, nas atividades como a derrubada da roça, o ralar mandioca, o esquartejar um jabuti ou uma preguiça, a dureza dos elementos é depreendida de uma prática onde o corpo dos homens e tais seres se engajam mutuamente, possibilitando categorizar mandiocas ou árvores como duras e não duras, constatar a resistência à morte de um jabuti ou a rigidez da cabeça de uma preguiça, em outros momentos a dureza passa a figurar como elemento para constituir o corpo dos homens, torna-se afecção ao produzir transformações por meio da mistura de corpos.

Tais transformações são executadas sempre a partir de um nível elementar de categorização, o qual está a meio caminho entre categorias mais inclusivas (genéricas) e categorias mais restritas (específicas) que têm como polo extremo os indivíduos (os espécimes). Ao ser agenciado para uma produção controlada de transformações, esse nível elementar opera como índice e eclipsa uma série de qualidades sensíveis dispostas em cascata. A noção de "imagem quimérica" de Severi (2013, ver também Severi e Lagrou 2013) parece guardar alguma semelhança com a noção de índice que estou empregando aqui. Tomando os grafismos indígenas (em especial dos Wayana, grupo vizinho e relacionado aos wajãpi por diversos eixos) como uma representação quimérica, Severi aponta para a presença de uma extensão invisível nesses desenhos; a imagem quimérica "[...] se caracteriza pela condensação da imagem em alguns traços essenciais. [...] Aquilo que pode ser visto é considerado, implicitamente, uma parte de outra forma, cuja presença é imputada e eventualmente representada" (Severi 2013: 26). Um dos efeitos dessas operações quiméricas é a intensificação do que não é visto ou, para ser coerente aos dados evocados pela etnografia wajãpi, do que não é percebido e captado pelos sentidos. Como também aponta Kohn (2013), o índice significa mais do que ele representa. Em suma, parece que os índices são eminentemente agentivos devido à sua característica de condensação de qualidades sensíveis e de um eclipsamento que permitem que os dentes do jaguar, por exemplo, possam ser percebidos por uma série de qualidades que não estão evidentes, ou seja, seguindo a noção de Severi, que se estendem para além do que é dado a perceber. Os dentes de jaguar em sua dimensão índice - que transforma corpos - tem uma relação de contiguidade (metonímica) com seu referente e dessa forma produz uma agência. ${ }^{16}$

Mas a dureza dos dentes de jaguar e da pedra tãsï (quartzo) não produz transformações nos seres que dela se aproximam o tempo todo, mas apenas em determinadas circunstâncias em que são operados como índice concreto para agenciar uma modificação através da mistura de corpos, momento em que a dureza, frieza e perenidade se apresentam como afecções. Nesse contexto, a

16 Essa relação entre a noção de "representação quimérica" de Severi e a forma como descrevo os índices, foi apontada por um dos pareceristas desse artigo, a quem sou muito grata pelo apontamento preciso. 
ontogênese de jaguar e dos homens é evocada e conectada a uma ação ou, para falar nos termos da discussão de Lévi-Strauss em O Pensamento Selvagem, se estabelece uma conexão entre mito e rito, entre classificação e ação.

A fala ocupa nesses processos uma posição central, uma vez que para os wajãpi ela é essencialmente eficaz e agentiva, é ela que dispara a ação. Além disso, é papel da fala recortar os aspectos de interesse na composição de capacidades e de características de corpos humanos. Num mundo onde a transformação é eminente, é perigoso estabelecer relações de consubstanciação completa com outros seres, pois arriscar-se-ia uma metamorfose sem volta. ${ }^{17}$ Por isso, as falas enunciam o aspecto que se deseja recortar para a composição da pessoa: a dureza de tãsï, a resistência da anta, a maleabilidade da língua de japiim, e assim por diante. Trata-se da construção da pessoa por meio de uma composição de afecções de outros sujeitos (humanos e não humanos). ${ }^{18}$

Enfim, é por meio da palavra, tanto em seu aspecto eficaz como em seu caráter nominalizador (de rotular categorias), que se manipulam as qualidades sensíveis de diferentes seres para produzirem alterações controladas que operam por meio de uma lógica do sensível, a qual perpassa e conecta os diferentes contextos aqui abordados. De um lado temos uma concepção de fala que permite unir classificação e ação. De outro, a lógica do sensível que também entrelaça taxonomia e agência, conectando sujeito e mundo duplamente: em um sentido, é o sujeito que age sobre um mundo, apreendendo corporal e intelectualmente as qualidades sensíveis dos entes que o povoam; em sentido oposto, são tais entes, em sua concretude, que atuam sobre os sujeitos, transformando-os. A relação sujeito-mundo se comunica e se altera mutuamente pelo concreto, pelo sensível, e por uma palavra que age.

Contudo, a fala (a palavra) não deve ser entendida como um viés exclusivo, de maneira a ocupar uma posição privilegiada na comunicação entre essa miríade de sujeitos. Apostando na ideia de comunicação em um sentido alargado, tal como propõem Bateson (1986) e recentemente Kohn (2013), ou seja, para além da linguagem articulada, a comunicação pode abarcar o próprio jogo sensível que se dá nas relações interespecíficas. Cada sujeito apresenta suas características e afecções, aspecto que pauta tanto os modos de relação como

17 Os wajãpi possuem um estado, denominado -awyry, no qual uma pessoa perde gradualmente sua perspectiva humana-wajãpi, passando a habitar o mundo de moju (sucuri). Essa situação é atribuída ao roubo do princípio vital (-'ã), operado por moju em retaliação pelo descumprimento de algum resguardo por parte da vítima (Cabral de Oliveira 2012). O estado -awyry se assemelha ao -jepota dos guarani mbya que, tal como discutido por Macedo (2009), trata-se da transformação de uma pessoa guarani em bicho, normalmente onça.

18 A respeito das afecções de sujeitos humanos, note-se que os wajãpi possuem muitos procedimentos de transmissão substancial de capacidades entre parentes, tais como passar suor em uma criança para que ela seja trabalhadora como o dono do suor, colocar a saliva de um bom cantador na boca de um neófito para que ele possa um dia apreender a cantar bem etc. 
a ação. Voltando a Lévi-Strauss, a ciência do concreto não é arbitrária como a relação entre significante e significado na língua; os animais, plantas e pedras são conhecidos num processo de engajamento minucioso entre humanos e não humanos; cada ente que compõe os enunciados eficazes, os mitos etc. é escolhido com precisão, em uma relação de contiguidade (metonímica). Assim, os homens se afetam, se dobram frente às especificidades de um japiim, de um jabuti, de uma helicônea que, assim, operam como sujeitos da relação.

\section{BIBLIOGRAFIA}

BATESON, Gregory, 1986, Mente e Natureza: Uma Unidade Necessária. Rio de Janeiro, Francisco Alves.

BERlin, Bert, 1992, Etnobiological Classification. Princeton, Princeton University Press.

CABRAl DE OliveirA, Joana, 2006, Classificações em Cena: Algumas Formas de Classificação das Plantas Cultivadas pelos Wajãpi do Amapari (AP). São Paulo, Universidade de São Paulo, dissertação de mestrado.

CABRAL DE OLIVEIRA, Joana, 2008, "Classificações em cena: algumas formas de classificação das plantas cultivadas pelos wajãpi do Amapari (AP)”, em Marc Lenaerts e Ana Maria Spadafora (orgs.), Pueblos Indígenas, Plantas y Mercados: Amazonía y Gran Chaco. Bucareste, Zeta Books, 29-58.

CABRAL DE OliveIRA, Joana, 2012, Entre Plantas e Palavras. São Paulo, Universidade de São Paulo, tese de doutorado.

GAlloIS, Dominique T., 1986, Migração, Guerra e Comércio: Os Waiãpi na Guiana. São Paulo, Universidade de São Paulo.

GAlloIS, Dominique T., 1988, O Movimento na Cosmologia Waiapi: Criação, Expansão e Transformação do Universo. São Paulo, Universidade de São Paulo, tese de doutorado.

GALlOIS, Dominique T., 1993, Mairi Revisitada: A Reitegração da Fortaleza de Macapá na Tradição Oral dos Waiãpi. São Paulo, Universidade de São Paulo e FAPESP.

GELL, Alfred, 1998, Art and Agency: An Anthropological Theory. Oxford, Clarendon Press.

HaraWAy, Donna, 2003, The Companion Species Manifesto: Dogs, People and Significant Otherness. Chicago, Prickly Paradigm Press.

HUNN, Eugene S., 1977, Tzeltal Folk Zoology: The Classification of Discontinuities in Nature. Nova Iorque, Academic Press.

INGOLD, Tim, 2000, The Perception of the Environment: Essays on Livelihood, Dwelling and Skill. Londres, Routledge.

INGOLD, Tim, 2010, "Da transmissão de representações à educação da atenção", Educação, 33 (1): 6-25.

KECK, Frédéric, 2004, Lévi-Strauss et la pensée sauvage. Paris, Presses Universitaires de France. KOHN, Eduardo, 2013, How Forests Think: Toward an Anthropology beyond the Human. Berkeley, University of California Press. 
LAKOFF, George, 1990, Women, Fire and Dangerous Things: What Categories Reveal about the Mind. Chicago, The University of Chicago Press.

LÉVI-STRAUSS, Claude, 1970 [1962], O Pensamento Selvagem. São Paulo, Editora da Universidade de São Paulo.

LÉVI-STRAUSS, Claude, 2004 [1964], O Cru e o Cozido. São Paulo, Cosac Naify .

MACEDO, Valéria M. de, 2009, Nexos da Diferença: Cultura e Afecção em Uma Aldeia Guarani na Serra do Mar. São Paulo, Universidade de São Paulo, tese de doutorado.

RAPINI, Alessandro, 2004, "Classes or individuals? The paradox of systematics revised", Studies in History and Philosophy of Biological and Biomedical Sciences, 35: 675-695.

ROSALEN, Juliana, 2005, Aproximações à Temática das DST junto aos Wajãpi do Amapari: Um Estudo sobre Malefícios, Fluidos Corporais e Sexualidade. São Paulo, Universidade de São Paulo, dissertação de mestrado em Antropologia Social.

SAUSSURE, Ferdinand, 1995 [1916], Curso de Lingüística Geral. São Paulo, Cultrix.

SEVERI, Carlo, 2013, "O espaço quimérico: percepção e projeção nos atos do olhar”, em Carlo Severi e Els Lagrou (orgs.), Quimeras em Diálogo: Grafismo e Figuração nas Artes Indígenas, Rio de Janeiro, 7 Letras, 25-66.

SEVERI, Carlo, e Els LAGROU, 2013, "Introdução”, em Carlo Severi e Els Lagrou (orgs.), Quimeras em Diálogo: Grafismo e Figuração nas Artes Indígenas. Rio de Janeiro, 7 Letras, $11-24$. 